\title{
Experimental Data in Vehicle Modeling
}

\author{
Maria Tomasikova $^{1 *}$, Dusan Sojcak $^{2}$, Aleksander Nieoczym $^{3}$ and Frantisek Brumercik ${ }^{1}$ \\ ${ }^{1}$ University of Zilina, Faculty of Mechanical Engineerings, Univerzitna 1, Zilina, Slovak Republic; \\ Email: maria.tomasikova@fstroj.uniza.sk,brumercikf@fstroj.uniza.sk \\ ${ }^{2}$ Enersense International Oy Gallen-Kallelankatu 7, 28100 Pori, Finland, Email: \\ dusan.sojcak.ext@areva.com \\ ${ }^{3}$ Lublin University of Technology, Faculty of Mechanical Engineering, Nadbystrzycka 36, 20-618 \\ Lublin, Poland, Email: a.nieoczym@pollub.pl
}

\section{*Corresponding Author: Maria Tomasikova}

\begin{abstract}
This article is about a vehicle model which is created in software Matlab Simscape Driveline. In this model the motor is created like a subsystem by Simulink blocks and input data were measured by single roller dynamometer for cars (SRD). Measured data are the input into the model by Lookup Table block. The vehicle model is made by gear, differential, tire and vehicle body blocks. We studied the forces on tires, the vehicle velocity and the slip.
\end{abstract}

Keywords: vehicle, simulation, model, Simscape, Lookup Table, vehicle

\section{Introduction}

Simulink is a block diagram environment for multidomain simulation and Model-Based Design. It supports simulation, automatic code generation, and continuous test and verification of embedded systems. Simulink provides a graphical editor, customizable block libraries, and solvers for modeling and simulating dynamic systems. It is integrated with Matlab, enabling you to incorporate Matlab algorithms into models and export simulation results to Matlab for further analysis.

This article is about motor simulation in Matlab software. We created the motor subsystem which represents real electric motor. The most important part of this subsystem is Look Up Table block processing the measured data [1,2].

\section{Input Data and Motor Map}

We are able to obtain a lot of information from measurements by single roller dynamometer for cars (SDR) and then we can use these data for simulation. SDR is equipped with precise axle regulation [3]. The maximum test speed is $320 \mathrm{~km} \cdot \mathrm{h}^{-1}$ and maximum power to the front / rear axle $1000 / 2000$ $\mathrm{kW}$. We are able to measure vehicles, which are all-wheel drive, including long-term endurance 
tests of high-performance vehicles without damaging of the tires because each wheel is placed on a separate roller. We measured the experimental electric vehicle Edison developed at University of Zilina. Fig. 1 shows the motor subsystem. This subsystem is created in Simulink by Look Up Table, Gain and Integrator blocks $[4,5]$.

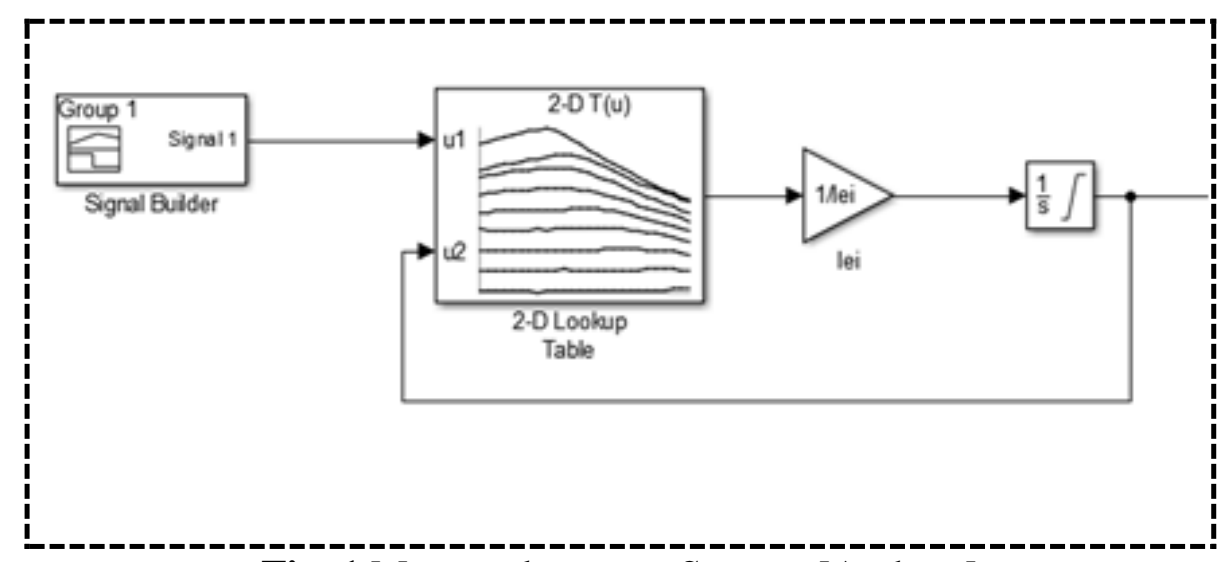

Fig. 1 Motor subsystem. Source: [Authors]

Mathematical expression of the motor subsystem [5] is described as

$$
\mathrm{M}=\mathrm{I} . \alpha=\mathrm{I} . \mathrm{d} \omega / \mathrm{dt}, \quad[\mathrm{N} . \mathrm{m}]
$$

where: $M$ is torque $[\mathrm{N} . \mathrm{m}] ; I$ is Inertia $\left[\mathrm{kg} \cdot \mathrm{m}^{2}\right] ; \alpha$ is angular acceleration $\left[\mathrm{rad} . \mathrm{s}^{-2}\right] ; \omega$ is angular velocity $\left[\mathrm{s}^{-1}\right] ; t$ is time $[\mathrm{s}]$.

The measured data are input for the 2-D Lookup Table block. In this block we can see the motor map (Fig. 2). This subsystem is further used like the motor for simulation of the electric vehicle [6, 7].

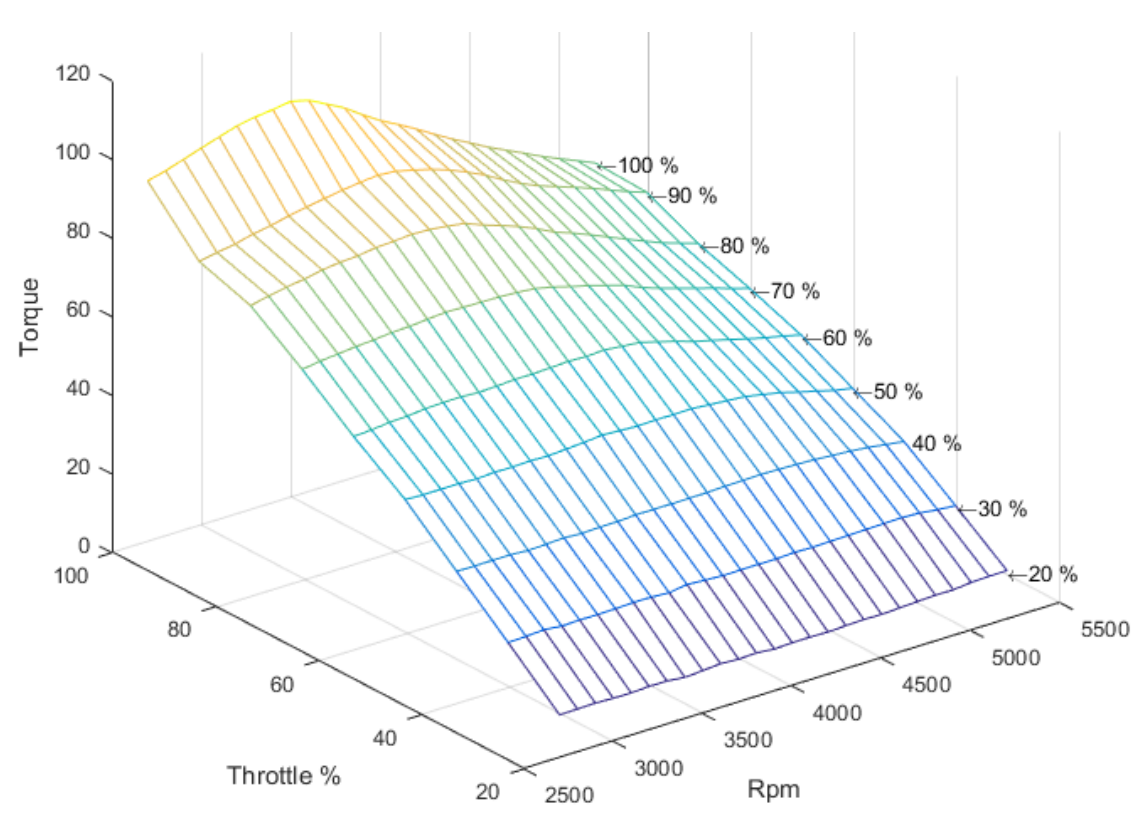

Fig. 2 Motor map. Source: [Authors] 
Output of the motor subsystem is connected with an Ideal Angular Velocity Source and with vehicle model, which is made in Simscape Driveline. The Simulink-PS Converter has to be used to connect Simulink blocks with Simscape blocks [8]. The block scheme of the vehicle model is shown in Fig. 3.

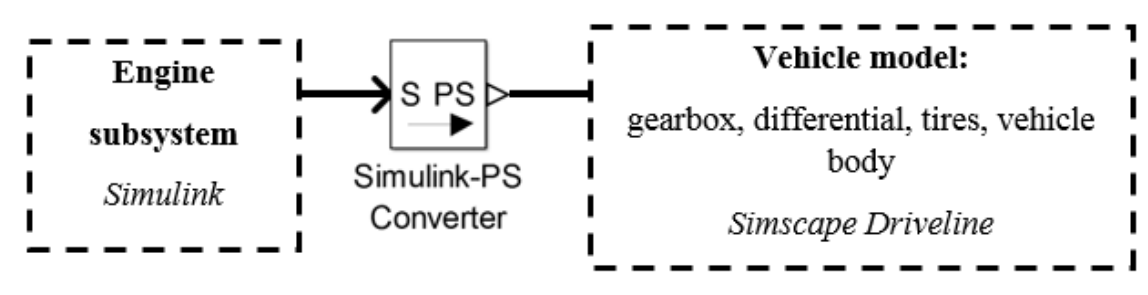

Fig. 3 Block scheme of the vehicle model. Source: Authors

The vehicle model is created by gearbox, differential, tires and vehicle body subsystem blocks [9, 10]. The vehicle has driven the rear axle. Table 1 represents input parameters of the electric car, which are necessary for simulation.

Table 1 Vehicle input parameters. Source: [Authors]

\begin{tabular}{|c|c|}
\hline Parameter & Value [unit] \\
\hline Initial velocity & $0\left[\mathrm{~min}^{-1}\right]$ \\
\hline Rolling radius & $0.3[\mathrm{~m}]$ \\
\hline Longitudinal stiffness & $200000\left[\mathrm{~N} \cdot \mathrm{m}^{-1}\right]$ \\
\hline Longitudinal damping & $1000\left[\mathrm{~N} .\left(\mathrm{m} \cdot \mathrm{s}^{-1}\right)^{-1}\right]$ \\
\hline Mass & $1050[\mathrm{~kg}]$ \\
\hline Horizontal distance from CG to front axle & $1.4[\mathrm{~m}]$ \\
\hline Horizontal distance from CG to rear axle & $1.6[\mathrm{~m}]$ \\
\hline CG height above ground & $1.2[\mathrm{~m}]$ \\
\hline Slope & $0\left[^{\circ}\right]$ \\
\hline Frontal area & $3\left[\mathrm{~m}^{2}\right]$ \\
\hline Drag coefficient & $0.4[-]$ \\
\hline
\end{tabular}

Fig. 4 shows the complete vehicle model developed in Simscape Driveline environment. We studied forces and slip on tires and the velocity of the vehicle body. 


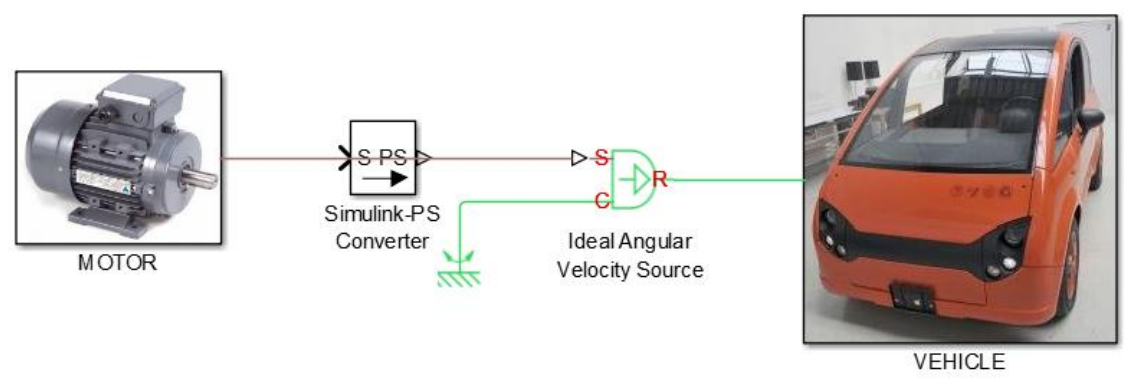

Fig. 4 Masked model in Simscape SimDriveline environment. Source: Authors

This vehicle model allows us to measure different variables as the resulting vehicle velocity, forces acting on a tire and the tire slip. The tire (Magic Formula) [10, 11] block assumes longitudinal motion only and includes no camber, turning, or lateral motion.

\section{Simulation Conditions and Results}
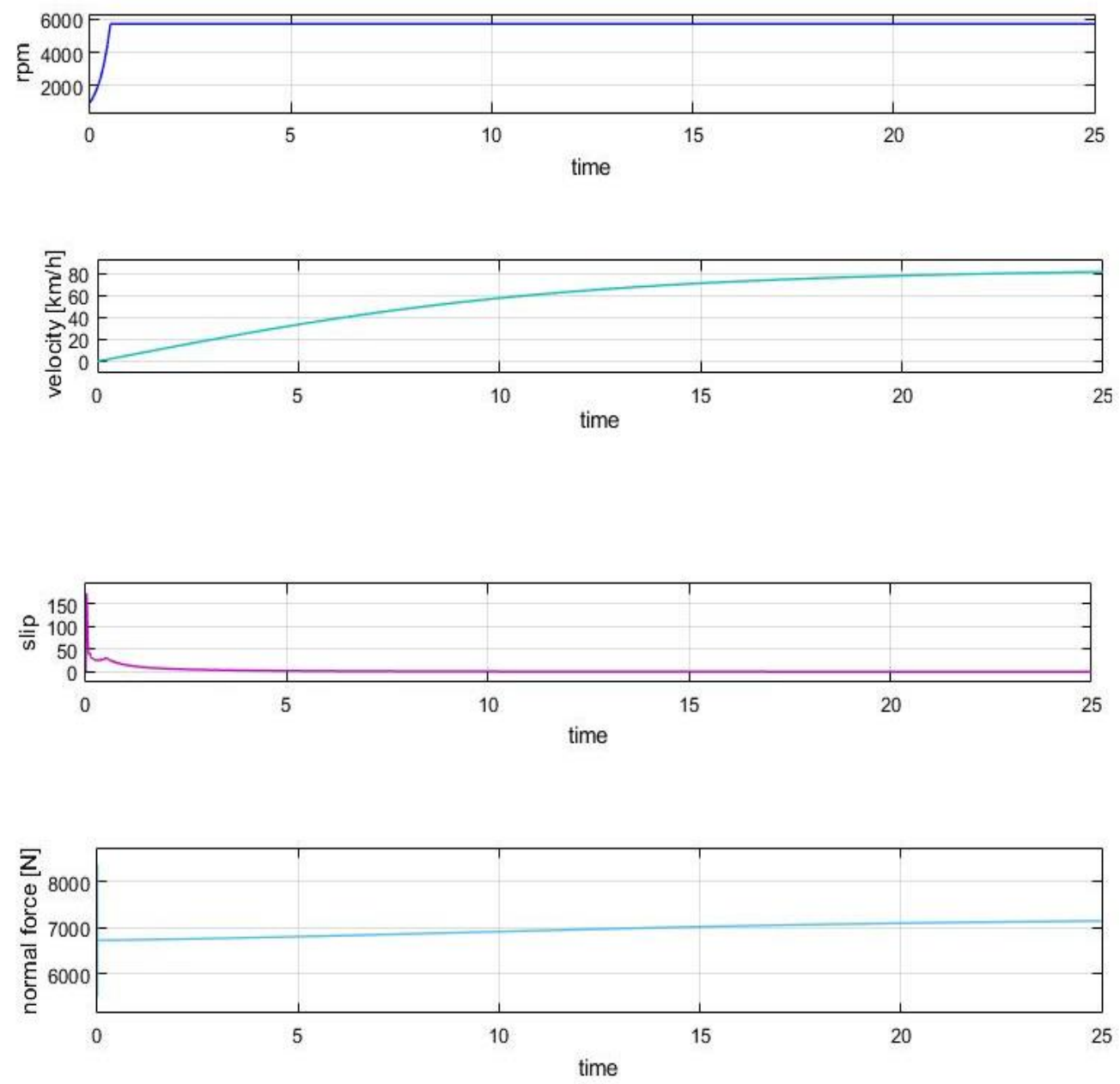

Fig. 5 Simulation results. Source: [Author] 
Results of the simulation are shown in Fig. 5. We can see the motor speed, vehicle velocity, normal force and slip time progress.

The used simulation solver was ode15s. This is one of many solvers, which we can use for simulation in Simscape Driveline [12]. It computes the model's state at the next time step using variable-order numerical differentiation formulas (NDFs). These are related to, but more efficient than the backward differentiation formulas (BDFs), also known as Gear's method. The ode15s is a multistep solver, and thus generally needs the solutions at several preceding time points to compute the current solution [13].

\section{Conclusion}

Modeling in Simscape Driveline is very effective. We are able to model a complete car transmission by using just a few blocks. Input parameters can be easily changed in the workspace [14]. We used the electric motor map measured in laboratory conditions using SDR as the input data. We created the motor subsystem which represent real electric motor. The most important part of this subsystem is Look Up Table block processing the measured data. The vehicle model is created by blocksgearbox, differential, tires and vehicle body subsystem in Simscape Driveline. There are also studied the forces on tires and velocity of the vehicle. Chapter 3 is about Simulation conditions and results This model can be used for further simulations editing the block input parameters such as motor power, vehicle dimensions, track slope, etc.

\section{Acknowledgments}

This paper presents results of work supported by the Slovak Scientific Grant Agency of the Slovak Republic under the project No. VEGA 1/0077/15.

\section{References}

[1] Kohar, R. \& Hrcek, S. (2014). Dynamic analysis of a rolling bearing cage with respect to the elastic properties of the cage for the axial and radial load cases. Communications, 16 (3A), 74-81. ISSN 1335-4205.

[2] Hrcek, S., Kohar, R. \& Medvecky, S. (2012). Determination on the maximum roller bearing load with regards to durability thereof using FEM analysis. Communications, 14 (3), 55-61. ISSN 1335-4205.

[3] Drozdziel, P., Brumercikova, E. \& Bukova, B. (2015). The Use of Progressive Methods of Serving Passengers. Transport problems, 10 (4). ISSN 1896-0596. 
[4] Nieoczym, A. (2005). Application of a transportation flux for determining qualitative indices. Communications, 7 (1), 47-48. ISSN 1335-4205.

[5] Kucera, L., Lukac, M., Jurak, L. \& Brumercik, F. (2009). Hydromechanical Automatic Transmission. Communications, 11 (2), 33-35. ISSN 1335-4205.

[6] Drozdziel, P. \& Krzywonos, L. (2009). The Estimation of the Reliability of the First Daily Diesel Engine Start-up During its Operation in the Vehicle. Eksploatacja i Niezawodnosc Maintenance and Reliability, 1 (41), 4-10. ISSN 1507-2711.

[7] Jedlinski, L., Caban, J., Krzywonos, L., Wierzbicki, S. \& Brumercik, F. (2015). Application of vibration signal in the diagnosis of IC engine valve clearance. Journal of Vibroengineering, 17 (1), 175-187. ISSN 1392-8716.

[8] Lukac, M., Brumercik, F., Krzywonos, L. \& Drozdziel, P. (2014). Tension mechanism dynamic analysis. Communications, 16 (3A), 184-188. ISSN 1335-4205.

[9] Filo, M. \& Lukac, M. (2005). Modeling and Simulation of Mechanisms with Computer Support, Zilina: EDIS- publisher of University of Zilina, ISBN 80-8070-466-X.

[10] Caban, J., Drozdziel, P., Vrabel, J., Sarkan, B., Marczuk, A., Krzywonos, L. \& Rybicka, I. (2016). The research on ageing of glycol-based brake fluids of vehicles in operation. Advances in Science and Technology, 10 (32), 9-16. ISSN 2299-8624.

[11] Caban, J., Marczuk, A., Sarkan, B. \& Vrabel, J. (2015). Studies on operational wear of glycolbased brake fluid. Przemysł Chemiczny, 94 (10), 1802-1806. ISSN 0033-2496.

[12] Faturik, L., Trsko, L., Hrcek, S. \& Bokuvka, O. (2014). Comparison of structural design in high and ultra-high cycle fatigue regions. Transactions of FAMENA, 38 (4), 1-12. ISSN 13331124

[13] Marczuk, A., Caban, J., Savinykh, P., Turubanov, N. \& Zyryanov, D. (2017). Maintenance research of a horizontal ribbon mixer. Eksploatacja i Niezawodnosc - Maintenance and Reliability, 19 (1), 121-125. ISSN 1507-2711.

[14] Walczak, M., Zwierzchowski, M., Bienias, J. \& Caban, J. (2017). The tribological characteristics of Al-Si/graphite composite. Tribologia, 1, 97-104. ISSN 0208-7774. 